\title{
Misuse of Medicines in the European Union: A Systematic Review of the Literature
}

\author{
Alicia Casati $^{a}$ Roumen Sedefov ${ }^{b}$ Tim Pfeiffer-Gerschel ${ }^{a, c}$ \\ ${ }^{a}$ Institut für Therapieforschung, Munich, Germany; ${ }^{b}$ European Monitoring Centre for Drugs and Drug Addiction \\ (EMCDDA), Lisbon, Portugal; ' German Focal Point of the EMCDDA, Munich, Germany
}

\section{Key Words}

Abuse of prescription drugs - Dependence on prescription drugs · Analgesics/opioids · Sedatives $\cdot$ Heroin maintenance treatment $\cdot$ European Union - Medicine misuse

\begin{abstract}
Background: Although awareness of the misuse of medicines is increasing, data on the extent of the problem in the European Union (EU) are lacking. Methods: In order to assess the magnitude and severity of the problem, a systematic review of the literature on the misuse of analgesics, opioid substitution medicines and sedatives/hypnotics (with the exception of benzodiazepines) was conducted using the PubMed and Web of Science databases. Relevant literature was identified between 2001 and 2011. Results: The main groups of misused medicines include opioid analgesics, methadone, buprenorphine and Z-drugs. Regional trends in medicine misuse indicate heterogeneity across the EU with respect to misused medicine types and research activities. Prevalence, high-risk populations and factors contributing to medicine misuse are discussed. Conclusion: The implications of these findings for prevention, treatment, and policy in the EU are considered.

Copyright $\odot 2012$ S. Karger AG, Basel
\end{abstract}

\section{Introduction}

Medicines such as analgesics, opioid substitution drugs, sedatives and hypnotics are increasingly being misused to induce psychoactive effects or to alter the effects of other consumed drugs, potentially resulting in dependence. Other types of misuse such as increasing dosages without medical supervision and without the objective of inducing psychoactive effects may also lead to negative health consequences. Medicine misuse is a broad term which encompasses many different types of problematic consumption. Awareness of medicine misuse, especially prescription medicine misuse, has been increasing in the past few years and organizations such as the United Nation's International Narcotics Control Board predict that worldwide misuse of prescription drugs will soon exceed illicit drug use [1]. This alarming prediction has been found to be an increasing reality in countries like the USA, where prescription drug misuse is second only to marijuana use across all age groups [2]. Similar alarming figures have been found for European countries. For example, estimates show that between 1.3 and 1.4 million Germans are dependent on prescription drugs. This corresponds to approximately 1.6 or $1.7 \%$ of the German population [3]. To date, literature on the ex-

\section{KARGER}

Fax +4161306 1234

E-Mail karger@karger.ch

www.karger.com
(C) 2012 S. Karger AG, Basel

$1022-6877 / 12 / 0185-0228 \$ 38.00 / 0$

Accessible online at:

www.karger.com/ear
Alicia Casati

Institut für Therapieforschung

Parzivalstrasse 25

DE-80804 Munich (Germany)

Tel. +49893608 0443, E-Mail casati@ift.de 
tent of the phenomenon in the European Union (EU) is very scarce, limiting our understanding of the problem on a European level.

Blanco et al. [4] propose that the increased availability of these drugs over the internet and through increased medical prescriptions could be key aspects of the increasing prevalence of substance use disorders related to medicine misuse. As a consequence of the increased demand for prescription drugs for the purpose of misuse, counterfeit production of medicines has also boomed. Furthermore, internet sales have additionally been found to play an important role in the distribution and increased availability of counterfeit prescription medicines [5]. Other key aspects of medicine misuse, especially among recreational and dependent opioid users, include the legal status und controlled quality production of prescription medicines. Opioid-dependent subjects reportedly have an inclination towards medicine misuse because prescription drugs are more easily obtained than illegal drugs, the likelihood of arrest for their trafficking is smaller than for illegal drugs, their misuse is more socially acceptable, they are purer and have predictable dosages (which reduces health-associated risks), and they can be used as substitutes for heroin or for self-medication to relieve withdrawal symptoms [6]. Some of these motives could be generalized to the misuse of prescription medicines to other groups of people, given that the perceived advantages apply to many different types of medicines.

The aim of this paper is to present results of a systematic review of the literature on the misuse of medicines in the EU. Main topics include an assessment of the extent of the problem of medicine misuse and dependence for different types of medicines, a description of the populations that are particularly at risk of engaging in medicine misuse, and a characterization of patterns of misuse and factors related to misuse. The review focuses on the misuse of analgesics, opioid substitution medicines and Zdrugs. Although from a pharmacological and clinical perspective, the inclusion of benzodiazepines in this review would be justified, more predominant factors have led to their exclusion from this review. From a historical perspective, the great misuse and dependence potential for benzodiazepines has been well established in the scientific literature. In contrast, Z-drugs are a relatively new class of nonbenzodiazepine hypnotics for which a great deal of discussion on misuse and dependence potential continues to take place, which is why they have been included in this review. Furthermore, the volume of the literature on benzodiazepine misuse and dependence is so extensive that we consider a review on this topic to be a project on its own. It is worth mentioning that, to the best of our knowledge, no systematic review of the literature on the misuse and dependence on benzodiazepines in the EU has been published until now. Nevertheless, for a small sample of the European literature on benzodiazepine misuse and dependence, see references 7-19. Additionally, the misuse of anabolic steroids in the context of sports has also been excluded. For examples of overview literature on this topic, see references 20-26.

\section{Methods}

One of the difficulties regarding the literature on medicine misuse lies in the great variability and inconsistency of the terminology used to describe this phenomenon. Terms such as 'overthe-counter' and 'prescription' differentiate between the types of misused medicines based on their controlled status. However, the controlled status of a medicine can change over time and can differ between countries. Some definitions attempt to describe the type of use based on adjectives (e.g. nonmedical use, problem use, harmful use, inappropriate use), which calls into question whether these terms are clearly defined cross-country terms and whether there is a consensus on the negative consequences (i.e. problem, harm) of use that are required to classify this type of consumption. Other terms attempt to define use based on motives (e.g. recreational use, self-medication), raising as many questions as the previous terms. Many of the terms used describe types of use which are often overlapping but do not necessarily refer to the same thing. A similar problem appears when classifying disorders associated with medicine misuse (e.g. ambiguity between terms such as addiction and dependence). A number of researchers have highlighted this problem. For example, Barrett et al. [27] discuss the current problems with the conceptualization of medicine misuse and point to the fact that there is no current consensus on terminology. The current International Classification of Diseases $(\mathrm{ICD}-10)^{1}$, published by the World Health Organization, uses the terms 'dependence syndrome' and 'harmful use' while the current Diagnostic and Statistical Manual of Mental Disorders (DSMIV), published by the American Psychiatric Association [28], uses the terms 'substance dependence' and 'substance abuse'. Although the criteria for these diagnoses partially concur, they are not identical. Additionally, even though these are the most used manuals for classifying disorders related to substance misuse, many research groups use alternative terms. The variability of definitions between and within studies makes the comparison of results across studies, the interpretation and generalization of results and the determination of the magnitude of medicine misuse extremely difficult [27]. For this reason, we will use the term 'misuse' as a general term which describes all types of medicine use in which some form of problematic consumption has been established. For

Seehttp://www.who.int/classifications/icd/en/, accessed online on February $22,2011$. 
example, the use of a medicine, with or without a doctor's prescription, clearly outside of accepted medical practice or guidelines, for recreational purposes or in the framework of self-medication, in greater dosages or for longer periods than were prescribed, in which the risks and problems associated with use outweigh the benefits. We will use 'misuse' as an umbrella term to include all types of use mentioned above. This term is neither intended to make a diagnosis nor to imply negative connotations with regard to the intention of use. We will use the term 'dependence' when reporting on the ICD-10 dependence syndrome and the DSM-IV substance dependence diagnoses.

A systematic review of the literature was conducted using Web of Science and PubMed. The original literature searches (1 Web of Science search and 2 PubMed searches) were carried out in January 2011. For all searches, a 10-year restriction on publication year was applied. No restrictions were placed on language or manuscript types although all search terms were in English. Terms were searched for within titles, abstracts and key words. The general search method encompassed two main components: misuse and medicines. For the first component, a number of synonyms and related terms for misuse were included in the search (e.g. addiction, dependence, nonprescription use, nonmedical use). Similarly, for the second component, multiple terms referring to medicines and substitution treatment were employed (e.g. prescription drug, over-the-counter drug, analgesic, tranquilizer, hypnotic, methadone, buprenorphine, antidepressant, opioid replacement therapy, substitution treatment). The PubMed searches were restricted to publications on humans, as this limitation was offered. The first PubMed search was performed using $\mathrm{MeSH}$ terms (e.g. substance-related disorders, pharmaceutical preparations, substance abuse detection, pharmacoepidemiology). Because this search resulted in few hits relevant to medicine misuse in the EU, a second PubMed search was performed under the same principle of the main components listed above. For the second PubMed search, terms were mainly extracted from the PubMed index (e.g. medicine misuse, prescription medication misuse, nonmedical drug use, nonprescription drug use, prescription drug addiction). Additionally, the literature was searched for references to all EU countries (as well as Croatia, Norway and Turkey) and to additional subjects (e.g. prevalence, doctor shopping, online purchase, pharmacovigilance). The misuse of benzodiazepines and anabolic steroids in the context of sports was excluded from the literature searches.

Over 800 sources resulted from the Web of Science and PubMed searches. Of these, a great number were filtered out due to irrelevance and fulfillment of exclusion criteria (e.g. benzodiazepine misuse, non-EU country). After narrowing the initial outcome, a total of 57 relevant references were included in the analysis. 'Relevant' sources refer to those that were found using this search method, were thematically applicable to the misuse of medicines in the EU, and did not meet exclusion criteria. An update of the literature search was conducted in June 2011 using the same methodology as for the previous searches, except that a 6 -month restriction on publication date was set instead of the original 10-year restriction. A total of 57 new literature hits resulted from this updated search. After filtering irrelevant literature (using the same methodology as in the previous searches), 8 sources remained. A grand total of 65 relevant sources were included in this analysis.

\section{Results}

The main misused groups of medicines found were analgesics, opioid substitution drugs, and sedatives/hypnotics. For each of these medicine types, the most relevant publications on patterns of misuse, factors related to misuse, and high-risk groups will be presented below. Other medicines, such as antidepressants [29], antiparkinson drugs [30,31], cough and cold medicines [32, 33], and stimulants, such as methylphenidate [34, 35], have also been found to be misused. However, the literature on these drug types is limited in comparison to the main groups of misused medicines listed above. The geographic distribution of the literature found is pictured in figure 1 , with certain countries providing multiple hits (e.g. France, Germany, UK) and others none (e.g. Romania, Bulgaria, Latvia). For this reason, our analysis focuses on portraying medicine misuse on a European level instead of for individual member states.

\section{Analgesics}

Analgesics make up an important part of misused medicines for multiple reasons. These drugs represent a significant proportion of medicine sales and are in part easily accessible to the general public, as is the case with over-the-counter analgesics. Twenty-four percent of overthe-counter medicine sales in the UK in 2001 were traced back to analgesics, making them the most commonly used nonprescription medicines [36]. In the UK, a number of prescription medicines, among them analgesics, have been re-classified as nonprescription to increase their accessibility and encourage self-care of minor illnesses [33]. Even though availability alone does not lead to increased misuse, it does contribute to the proliferation and consumption of the drug, which, in combination with other factors, such as diversion potential and the development of tolerance can contribute to the likelihood of misuse and dependence. With regard to prevalence rates, a cross-sectional postal survey of adults (18+ years old) in Scotland found that the past 2-week prevalence of nonprescription analgesic use was $37 \%$ [36]. Women and people under the age of 60 were found to be more likely to use nonprescription analgesics although the latter is a controversial subject in the literature. Of the nonprescription analgesic users included in the study, $21 \%$ reported some type of misuse. Additional evidence from Germany shows that the prevalence of dependence on analgesics in a representative sample of general hospital patients was 
Fig. 1. Overview of the discussed literature hits in the EU.

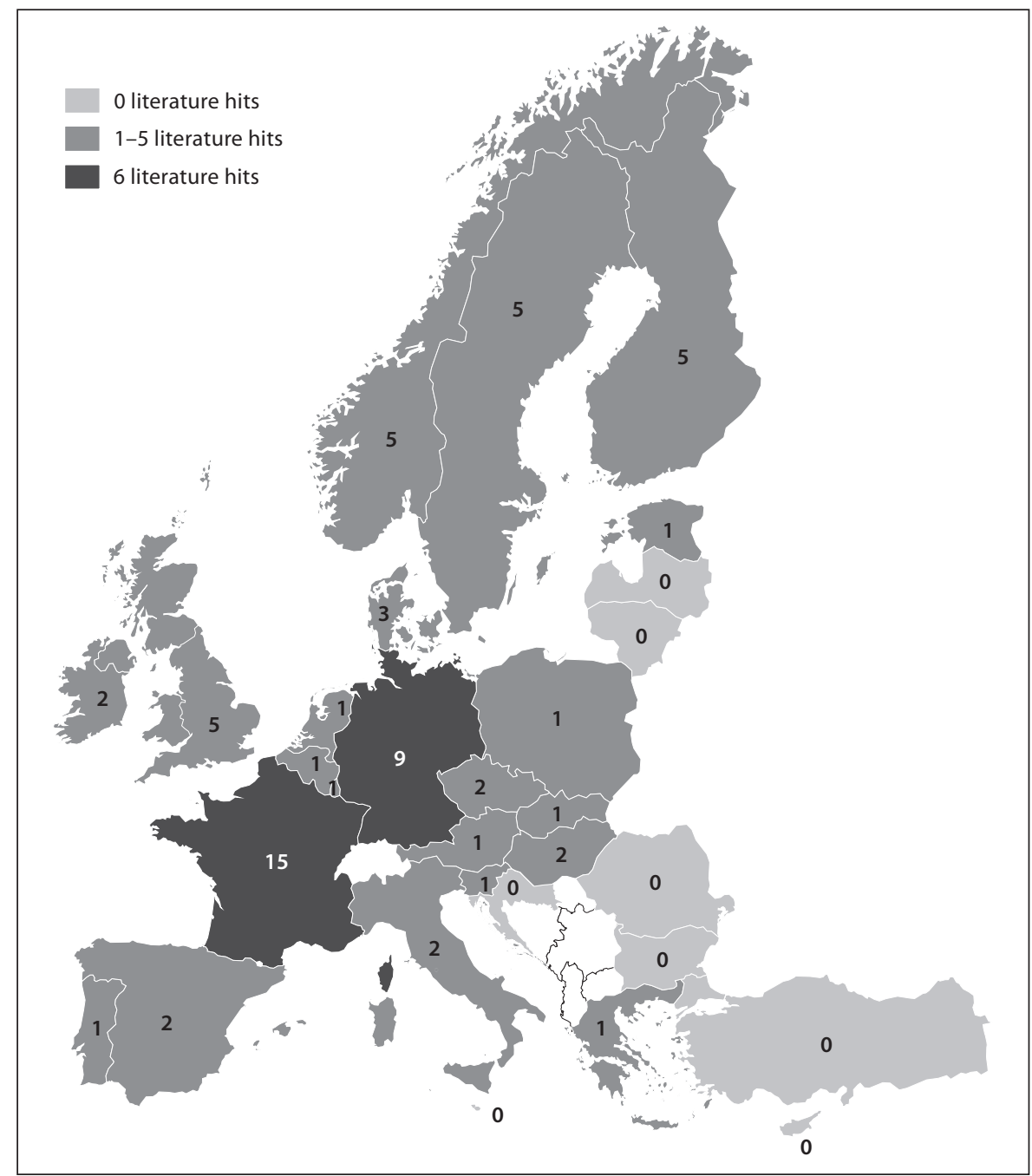

$1.3 \%$ [37]. Further studies revealed information on the misuse of codeine, tramadol, fentanyl, triptans and ergot derivatives, and carisoprodol.

\section{Codeine}

French and Norwegian studies found misuse prevalence rates for codeine, an opiate analgesic used to treat mild to moderate pain. According to a study based on the Norwegian prescription database, $0.5 \%$ of subjects with at least one codeine prescription exceeded the maximum recommended dose of 730 defined daily doses (DDDs) of codeine per year [38]. Of these subjects, $65 \%$ were comedicated with benzodiazepines and $45 \%$ with carisoprodol. This comedication is discouraged for the treatment of chronic nonmalignant pain according to Norwegian medical recommendations. Patients who display such problematic codeine consumption patterns are at in- creased risk of developing dependence. In France, a crosssectional pilot study based on data from community pharmacies found that among patients who used codeine in the past month, $15.1 \%$ misused it and/or used it for a nonmedical reason and $7.5 \%$ were cases of codeine dependence, according to DSM-IV criteria [32]. An additional French study on the misuse of neocodion, a codeine antitussive preparation, found a marked and continuous decrease in consumption between 1992 and 2002 [39]. Data for this study were collected via community networks of pharmacists and from the French drug dependence-monitoring program $\left(\mathrm{OPPIDUM}^{2}\right)$. Results further revealed that $86 \%$ of subjects misusing neocodion

2 OPPIDUM stands for 'Observation des produits psychotropes illicites ou détournés de leur utilisation médicamenteuse' (in French). It is an annual survey on the consumption of licit and illicit drugs. 
were polydrug consumers, pointing to the high comorbidity between drug misuse and medicine misuse. Neocodion was most commonly misused for its psychoactive effects. Codeine misuse is presumably widespread across other European countries, but the literature search did not yield further studies on this specific medicine.

\section{Tramadol}

Tramadol is a weak centrally acting opioid analgesic used to treat moderate to severe acute and chronic pain. Tjaderborn et al. [40] searched the Swedish Drug Information System (SweDIS), a database for spontaneously reported adverse drug reactions, for reports on tramadol dependence between 1995 and 2006. Of the adverse drug reactions reported to the SweDIS, 104 reports of tramadol dependence were identified using DSM-IV criteria. $58 \%$ of these cases concerned female patients and 39\% of the cases presented past or current substance abuse. General results of this study suggest that the typical individual at risk for misusing tramadol is a middle-aged person diagnosed with chronic or temporary pain, who is additionally being treated with at least one other psychotropic drug. Additionally, Tjaderborn et al. point to other studies, which identified that there is a $58 \%$ higher tramadol prescription rate for women than for men, which is mirrored by the higher rates of dependence for females. The development of dependence to tramadol may be a consequence of the poor efficacy of the drug, which has been shown to have lower analgesic effects than other opioid analgesics. Poor efficacy may lead to increasing doses, which in turn could lead to tramadol dependence.

Deaths caused by tramadol intoxication among drugdependent subjects notably increased between 2002 and 2007 in Finland and Sweden [41].

\section{Fentanyl}

Fentanyl is a potent opioid analgesic used as an anesthetic and to treat severe chronic pain (e.g. cancer pain). A French study on the prescription and misuse patterns of fentanyl (available in oral form under the trade name Actiq $^{\circledR}$ and in transdermal form under the trade name Durogesic ${ }^{\circledR}$ ) between 2007 and 2009 found that over 30\% of all prescriptions for the aforementioned trade brands were off-label prescriptions [42]. Furthermore, misuse rates for Actiq were assessed at 18.2, 13.2 and $13.7 \%$ for 2007, 2008 and 2009, respectively. Misuse rates found for Durogesic were 9.5, 18.6, and $8.2 \%$ in the same years. The authors conclude that fentanyl possesses a significant misuse and dependence potential.

\section{Triptans and Ergot Derivatives}

Triptans and ergot derivatives are anti-migraine medicines. In order to compare the risk of dependence associated with different classes of anti-migraine drugs, BeauSalinas et al. [43] conducted a study based on the side effects of drugs recorded in the French pharmacovigilance database. Of all reports involving triptans and ergot derivatives, 10.9 and $9.3 \%$ indicated substance dependence, respectively. The risk of dependence for these two drugs was found to be similar to the risk of dependence for benzodiazepines, which have a well-known potential for dependence and misuse. Additionally, recurring headaches have been found to promote drug overuse, which in turn could increase the risk of dependence, especially for medicines with high dependence potential. A related French study on the misuse of triptans in Alsace found similar risks for pain and chronic pain patients [44]. This study collected data from a prescription database of the French National Health's local health agencies and found that $25-30 \%$ of triptan use involved misuse. Furthermore, the higher the DDD for triptans, the higher the likelihood that patients would additionally consume analgesics (e.g. opiate analgesics such as codeine or tramadol).

\section{Carisoprodol}

Carisoprodol is a centrally acting muscle relaxant used in the treatment of acute lower back pain. Bramness et al. [45] investigated the prevalence of use and abuse of carisoprodol using data from the Norwegian Prescription Database. The prevalence of past-year prescription for carisoprodol was found to be $2.4 \%$ for adult females and $1.3 \%$ for adult men in 2004. One percent of patients were found to misuse carisoprodol alone, which suggests that pure carisoprodol misuse is rare. However, carisoprodol misuse in conjunction with benzodiazepine and opioid use appeared to be more common: $8 \%$ of all patients displayed a high concomitant use of benzodiazepines, suggesting they were anxiety patients or benzodiazepine misusers and $14 \%$ of all patients displayed a concomitant use of carisoprodol and opioids, suggesting primary opioid misuse. Fredheim et al. [38] also found that of subjects who exceeded the maximum recommended dose of codeine per year, $45 \%$ were also being comedicated with carisoprodol (see section on codeine). As compared to other European countries, Norway's sales of 2.4 DDDs of carisoprodol per 1,000 inhabitants per day were 7-8 times higher than in Spain, Sweden or Denmark. However, it is important to note that carisoprodol was back then the only centrally acting muscle relaxant on the market in 
Norway. Other countries such as France, Ireland and the Netherlands do not market carisoprodol. Given that only two references on carisoprodol resulted from the search, it is difficult to draw conclusions about the extent of the problem in Norway. No evidence could be derived from the searches on a European level. However, in 2007 the European Medicines Agency recommended the suspension of marketing authorizations for all medicinal products containing carisoprodol in light of the risk of misuse and dependence associated with it $^{3}$.

\section{High-Risk Groups for the Misuse of Analgesics}

As mentioned in the previous sections, the long-term treatment of pain with opioid analgesics bears the risk of the development of tolerance and dependence [46]. Approximately $2.2 \%$ of the European population uses weak analgesic opioids on a regular basis to treat chronic nonmalignant pain [38]. According to a review of the literature, prevalence rates for opioid dependence in chronic nonmalignant pain patients varied from 0 to $50 \%$, depending on the patient population studied and the criteria used [46]. Chronic daily or near-daily headache affects approximately $4-5 \%$ of the general population [47]. This subgroup of patients has a high risk of misusing analgesics, especially by overusing (i.e. using substances in greater dosages or for longer periods than prescribed) opioid analgesics. One third of these patients overuse migraine-abortive medicines, which often results in medication overuse headache $(\mathrm{MOH})$. A French study found that two thirds of $\mathrm{MOH}$ patients were dependent on migraine-abortive medicines according to DSM-IV criteria [47]. Furthermore, a significantly greater proportion of dependent $\mathrm{MOH}$ patients overused opiate-containing combinations as compared to nondependent patients. A Norwegian cross-sectional epidemiological study of subjects with secondary chronic headaches found that $49 \%$ overused migraine-abortive medicines [48]. According to this study, the most commonly overused migraineabortive medicines were over-the-counter analgesics such as paracetamol and ibuprofen, followed by codeinecontaining combinations.

Women and the elderly have also been found to be at increased risk of misusing medicine. Of Germans over age 60, between 1.7 and 2.8 million have been estimated to misuse psychoactive drugs or analgesics or are dependent on these substances, as reported by the German Centre for Addiction Issues [49]. The prevalence of potentially in-

\footnotetext{
3 Seehttp://www.ema.europa.eu/docs/en_GB/document_library/Press_ release/2009/11/WC500015582.pdf, accessed online on July 28th, 2011.
}

Misuse of Medicines in the European Union appropriate medicine use among noninstitutionalized adults over 65 years of age in Finland was found to be $14.7 \%$ in 2007 although this figure includes analgesic and nonanalgesic medicines [50]. Women have been found to be more likely to use nonprescription analgesics than men [36]. They are also more likely to be prescribed tramadol than men [40]. The higher medical exposure to tramadol through increased prescriptions may explain the higher rates of dependence among females.

Finally, subjects with a history of substance dependence, especially heroin/opioid dependence, are at increased risk of misusing opioid analgesic medicines. This comes as no surprise given that opioid analgesic medicine and illicit heroin can have similar pharmacological effects, which is why subjects often resort to this substance group when heroin is not available. A Spanish study on comorbidity of disorders among heroin-dependent patients in methadone maintenance treatment found that $11.6 \%$ had a lifetime prevalence rate for substance use disorder related to opioids other than heroin [51]. Subjects with a history of alcohol and sedative/hypnotic dependence may also be at increased risk of misusing analgesics. The Phar-Mon monitoring system, a German earlywarning system that tracks medicine misuse among subjects with substance use disorders currently in outpatient treatment, found that $14.3 \%$ of alcohol-dependent subjects and $12.2 \%$ of sedative/hypnotic-dependent subjects misused analgesics [29].

Table 1 displays a summary of the main reports on the misuse of analgesics.

\section{Medicines Used for Opioid Substitution Therapy}

Substitution substances are often misused alone or in combination with other licit or illicit substances, making misuse a central issue for the maintenance treatment of substance-dependent persons. Buprenorphine and methadone are the most commonly used substitution drugs to treat opioid dependence. Both of these drugs have high rates of misuse, including doctor shopping, illicit intravenous application, snorting, and buying and selling on the black market [52-55]. For the purposes of this review, doctor shopping refers to the practice of seeking out multiple physicians, often simultaneously, to obtain multiple prescriptions for medicines which would otherwise most likely not be prescribed in the same quantity or in the same manner by one single physician. Results on buprenorphine and methadone misuse have been presented below. 
Table 1. Selected literature on the misuse of analgesics in the EU

\begin{tabular}{|c|c|c|c|}
\hline Reference & Country/region & Type of study & Sample \\
\hline $\begin{array}{l}\text { Armand } \\
\text { et al. [39], } \\
2004\end{array}$ & France & OPPIDUM survey & $\mathrm{n} / \mathrm{a}$ \\
\hline $\begin{array}{l}\text { Astals et al. } \\
{[51], 2008}\end{array}$ & Spain & questionnaire & $\begin{array}{l}189 \text { opioid-dependent } \\
\text { subjects on methadone } \\
\text { maintenance treatment }\end{array}$ \\
\hline $\begin{array}{l}\text { Beau-Salinas } \\
\text { et al. [43], } \\
2010\end{array}$ & France & $\begin{array}{l}\text { case/noncase study } \\
\text { using reports on the } \\
\text { SEDs }\end{array}$ & $\begin{array}{l}449 \text { SED reports involv- } \\
\text { ing triptans, } 332 \text { SED } \\
\text { reports involving ergot } \\
\text { derivatives }\end{array}$ \\
\hline
\end{tabular}

Results

Neocodion was most commonly misused for its psychoactive effects. $86 \%$ of subjects misusing neocodion were polydrug consumers.

$11.6 \%$ of the subjects had a lifetime prevalence for substance use disorder related to opioids other than heroin.

Of reports involving triptans and ergot derivatives, 10.9 and $9.3 \%$ indicated dependence, respectively. Subjects with recurring headaches who use medication with a high potential for dependence have an increased risk of developing dependence disorders.

\begin{tabular}{|c|c|c|c|}
\hline $\begin{array}{l}\text { Bramness } \\
\text { et al. [45], } \\
2007\end{array}$ & Norway & $\begin{array}{l}\text { analysis of the Norwe- } \\
\text { gian Prescription Data- } \\
\text { base }\end{array}$ & $\begin{array}{l}53,889 \text { women and } \\
29,824 \text { men }(18+\text { years } \\
\text { old })\end{array}$ \\
\hline
\end{tabular}

Prevalence of past-year prescription for carisoprodol was $2.4 \%$ for women and $1.3 \%$ for men. $8 \%$ of patients displayed high concomitant use of benzodiazepines. $14 \%$ of patients displayed concomitant use of carisoprodol and opioids.

\begin{tabular}{|c|c|c|c|c|}
\hline $\begin{array}{l}\text { Fach et al. } \\
{[37], 2007}\end{array}$ & Germany & $\begin{array}{l}\text { self-administered } \\
\text { screening questionnaire } \\
\text { and structured psychi- }\end{array}$ & $\begin{array}{l}952 \text { general hospital } \\
\text { patients }\end{array}$ & $\begin{array}{l}1.3 \% \text { of sample displayed dependence on } \\
\text { analgesics. }\end{array}$ \\
\hline
\end{tabular}
and structured psychiatric interview

\begin{tabular}{llll}
\hline $\begin{array}{l}\text { Fredheim } \\
\text { et al. [38], }\end{array}$ & Norway & $\begin{array}{l}\text { analysis of the Norwe- } \\
\text { gian Prescription Data- }\end{array}$ \\
2009 & base
\end{tabular}

\begin{tabular}{lll}
\hline Gibaja et al. & France & survey of the Medical n/a \\
[42], 2011 & & Department of North \\
& East Social Security
\end{tabular} Misuse rates for Actiq fluctuated between 13.2 and $18.2 \%$ for $2007-2009$. Misuse rates for Durogesic fluctuated between 8.2 and $18.6 \%$ in the same time span. Fentanyl was found to possess a significant misuse and dependence potential.

\begin{tabular}{|c|c|c|c|c|}
\hline $\begin{array}{l}\text { Hojsted and } \\
\text { Sjogren [46], } \\
2007\end{array}$ & Denmark & literature review & chronic pain patients & $\begin{array}{l}\text { Prevalence rates of dependence for chronic } \\
\text { nonmalignant pain patients varied from } 0 \text { to } \\
50 \% \text {, depending on the patient population } \\
\text { studied and the criteria used. }\end{array}$ \\
\hline $\begin{array}{l}\text { Kufner and } \\
\text { Rosner [29], } \\
2008\end{array}$ & Germany & yearly questionnaire & $\begin{array}{l}\text { substance abusers attend- } \\
\text { ing outpatient treatment } \\
\text { facilities }\end{array}$ & $\begin{array}{l}14.3 \% \text { of alcohol-dependent subjects mis- } \\
\text { used analgesics. } 12.2 \% \text { of sedative/hypnotic- } \\
\text { dependent subjects misused analgesics. }\end{array}$ \\
\hline $\begin{array}{l}\text { MacFadyen } \\
\text { et al. [33], } \\
2001\end{array}$ & UK & $\begin{array}{l}\text { qualitative interview } \\
\text { and postal survey }\end{array}$ & $\begin{array}{l}24 \text { qualitative interviews } \\
\text { and a postal survey of } \\
110 \text { pharmacies }\end{array}$ & $\begin{array}{l}\text { Analgesics have increasingly been re-classi- } \\
\text { fied as nonprescription drugs, in line with } \\
\text { UK government policy which encourages } \\
\text { self-care of minor illnesses. }\end{array}$ \\
\hline
\end{tabular}


Table 1 (continued)

\begin{tabular}{|c|c|c|c|c|}
\hline Reference & Country/region & Type of study & Sample & Results \\
\hline $\begin{array}{l}\text { Orriols et al., } \\
\text { [32] } 2009\end{array}$ & France & $\begin{array}{l}\text { CEIP cross-sectional } \\
\text { pilot study }\end{array}$ & 817 subjects & $\begin{array}{l}\text { Among subjects who used codeine in the } \\
\text { past month, } 15.1 \% \text { presented misuse. } 7.5 \% \\
\text { were cases of codeine dependence. Of } \\
\text { patients who used pseudoephedrine in the } \\
\text { past month, } 15.6 \% \text { presented misuse. }\end{array}$ \\
\hline
\end{tabular}

\begin{tabular}{|c|c|c|c|}
\hline $\begin{array}{l}\text { Perearnau } \\
{[44], 2006}\end{array}$ & France & $\begin{array}{l}\text { analysis of prescription } \\
\text { database of the French } \\
\text { National Health's local } \\
\text { health agencies }\end{array}$ & 20,686 subjects \\
\hline
\end{tabular}
past month, $15.6 \%$ presented misuse.

$25-30 \%$ of triptan use involved misuse. The higher the DDD for triptans, the higher the likelihood that patients would additionally consume analgesics (e.g. opiate analgesics such as codeine or tramadol).

\begin{tabular}{|c|c|c|c|}
\hline $\begin{array}{l}\text { Porteous } \\
\text { et al. [36], }\end{array}$ & UK (Scotland) & $\begin{array}{l}\text { cross-sectional postal } \\
\text { survey }\end{array}$ & $\begin{array}{l}2,708 \text { subjects } \\
(18+\text { years old })\end{array}$ \\
\hline
\end{tabular}

Past 2-week prevalence of nonprescription analgesic use was $37 \%$. Women were found to be more likely to use non-prescription analgesics than men.

\begin{tabular}{|c|c|c|c|c|}
\hline $\begin{array}{l}\text { Radat et al. } \\
{[47], 2008}\end{array}$ & France & $\begin{array}{l}\text { cross-sectional multi- } \\
\text { center study }\end{array}$ & $\begin{array}{l}247 \mathrm{MOH} \text { patients from } \\
\text { headache specialty cen- } \\
\text { ters }\end{array}$ & $\begin{array}{l}66.8 \% \text { of } \mathrm{MOH} \text { patients were dependent on } \\
\text { migraine-abortive medication according to } \\
\text { DSM-IV criteria. }\end{array}$ \\
\hline
\end{tabular}

$\mathrm{SED}=$ Side effects of drugs

\section{Buprenorphine and Methadone}

In many cases, the problem of methadone or buprenorphine misuse begins even before the subjects enter maintenance treatment programs. Cazorla et al. [56] found that 84,000 opioid users were undergoing substitution maintenance treatment in France in 2001. Among these patients, $88 \%$ were being treated with buprenorphine and 37\% reported having used buprenorphine for the first time without having had a prescription for it. In 2008 , an Irish study found even higher rates of methadone misuse before treatment entry among patients in substitution treatment for opioid dependence [54]. 73\% of participants reported methadone misuse prior to entering treatment while 55\% reported methadone misuse during treatment. Participants reported misusing methadone primarily to manage opiate withdrawal symptoms but also for hedonistic effects. A German study on opiatedependent patients admitted to a detoxification ward found that $53.5 \%$ of patients misused medical opiates, especially methadone [53]. For this patient group, methadone misuse was usually motivated by difficulties in acquiring heroin. Other reasons included self-detoxifica- 
tion and using methadone as a transition before entering drug substitution treatment.

A more recent Italian study on heroin-dependent patients undergoing maintenance treatment found that $23.1 \%$ of patients reported intravenous misuse of buprenorphine [52]. Patients receiving buprenorphine maintenance therapy were significantly more likely to inject buprenorphine intravenously ( 35.5 vs. $17.8 \%$ ) than those receiving methadone. $50.7 \%$ of patients reported injecting buprenorphine in order to treat their heroin dependence or to reduce withdrawal symptoms while only $12.7 \%$ of patients reported doing so to experience pleasure or euphoria. Subjects were additionally asked to assess the number of patients receiving buprenorphine who have attempted to take it intravenously. Approximately half of the subjects (45.9\%) thought that at least $50 \%$ of patients on buprenorphine replacement treatment had injected buprenorphine intravenously, suggesting that the initial results may have underestimated the problem. A further study on buprenorphine misuse conducted by the Syringe Exchange Program in Malmo, Sweden, found that $43 \%$ of heroin and amphetamine users reported intravenous misuse of buprenorphine and 29\% reported snorting [57]. Additionally, 11\% of heroin users reported using street buprenorphine to induce euphoria compared to $62 \%$ of amphetamine users. A Finnish study on the abuse liability of buprenorphine-naloxone tablets among untreated intravenous-drug users found that buprenorphine is the most misused intravenous opioid in Finland [58]. In order to curb buprenorphine misuse, many treatment centers crush tablets before administering them to patients. Simojoki et al. [59] found that this practice does not significantly alter the clinical effect of the drug, indicating that it is an appropriate practice for reducing misuse.

In addition to buying and selling on the black market, doctor shopping is a widespread means of acquiring substitution substances. Pauly et al. [55] found that $13.2 \%$ of the reimbursed high-dosage buprenorphine was dispensed with prescriptions obtained by doctor shopping. Furthermore, results showed that the more a patient's profile was characterized by deviant behavior, the higher the indicator for doctor shopping. This study was based on data from the General Health Insurance System in one area of southern France. Other factors that have been hypothesized to be associated with doctor shopping are practitioners' prescribing practices and their attitudes towards patients. A French study on buprenorphine maintenance treatment found that doctor shopping was lower among general practitioners who reported induction of buprenorphine maintenance treatment with $8 \mathrm{mg}$ of buprenorphine per day or more, as compared to those who started treatment with less buprenorphine [60]. This study also found that doctor shopping was higher for general practitioners who displayed more stringent attitudes towards patients. Practitioners' 'stringent attitudes' during induction of buprenorphine maintenance treatment were defined as giving out prescription for 7 days only, with daily delivery by the pharmacist, with dose taking in the pharmacy. Using a simultaneous equation model, Feroni et al. [60] further found that practitioners' attitudes influence doctor shopping in patients, not the other way around. The authors suggested that doctor shopping is in part driven by physicians' conservative prescribing methods and attitudes towards patients, and not exclusively by 'deviant' patient behavior. They add that possible explanations for doctor shopping could include patients' dissatisfaction with general practitioners' care supply, inappropriate or insufficient care supply, and difficulties in the relationship between general practitioners and patients. The authors also call into question whether doctor shopping in this context reflects patients' dissatisfaction, rather than intended buprenorphine diversion, and suggest that further research is needed to clarify this. For additional general literature on the doctor-patient relationship and nonadherence to medication, see Stavropoulou [61].

Along the lines of prescribing practices, it has also been suggested that substandard opiate substitution prescription may lead to misuse. A recent study investigated the treatment practices and challenges of physicians treating opioid dependence in Germany, France, Italy and the UK [62]. Data for this study were collected through an online questionnaire from 300 physicians. When asked about prevalence rates for buprenorphine and methadone misuse, $72 \%$ of physicians reported that it was a 'huge' or 'significant' problem among patients. Regarding prescribing practices, the results also showed that mean methadone and buprenorphine maintenance doses were markedly subtherapeutic, as compared to recommended best practice. Additionally, the mean time taken to reach maintenance doses for buprenorphine was approximately 10 days longer than recommended by recent treatment guidelines. Bacha et al. [62] infer that these substandard prescribing practices are likely to increase the problem of methadone and buprenorphine misuse as well as to decrease compliance and treatment retention rates.

Finally, high rates of fatal poisoning have been found involving misuse of buprenorphine and methadone 
Table 2. Selected literature on the misuse of medicines used for drug substitution therapy in the EU

\begin{tabular}{lllll}
\hline Reference & Country/region & Type of study & Sample & Results \\
\hline $\begin{array}{l}\text { Alho et al. [58], } \\
2007\end{array}$ & Finland & survey & $\begin{array}{l}176 \text { attendees at a needle } \\
\text { exchange program }\end{array}$ & $\begin{array}{l}\text { Buprenorphine is the most misused } \\
\text { intravenous opioid in Finland. }\end{array}$ \\
\hline $\begin{array}{l}\text { Astals et al. [51], Spain } \\
2008\end{array}$ & questionnaire & $\begin{array}{l}189 \text { opioid-dependent } \\
\text { patients on methadone } \\
\text { maintenance treatment }\end{array}$ & $\begin{array}{l}71.4 \% \text { of subjects displayed more than one } \\
\text { lifetime substance dependence diagnosis } \\
\text { according to DSM-IV criteria. }\end{array}$ \\
\hline
\end{tabular}

Bacha et al. [62], Germany, online questionnaire 300 physicians

$2010 \quad$ France, Italy,

$\mathrm{UK}$

$72 \%$ of subjects reported that buprenorphine and methadone misuse among patients was a 'huge' or 'significant' problem. Mean methadone and buprenorphine maintenance doses were markedly subtherapeutic as compared to recommended best practice. Mean time taken to reach maintenance doses for buprenorphine was approximately 10 days longer than recommended by recent treatment guidelines.

\begin{tabular}{llll}
\hline $\begin{array}{l}\text { Cazorla } \\
\text { et al. [56], 2005 }\end{array}$ & France & retrospective study & 21 case reports \\
\hline $\begin{array}{l}\text { Feroni et al. [60], France } \\
2005\end{array}$ & telephone survey & $\begin{array}{l}\text { 546 GPs prescribing } \\
\text { buprenorphine } \\
\text { maintenance treatment }\end{array}$
\end{tabular}

$37 \%$ of subjects reported using buprenorphine for the first time without having a prescription for it.

Doctor shopping was lower among GPs who reported induction of buprenorphine maintenance treatment with $8 \mathrm{mg}$ of buprenorphine per day or more and for GPs who displayed more stringent attitudes towards patients.

\begin{tabular}{|c|c|c|c|}
\hline $\begin{array}{l}\text { Hakansson } \\
\text { et al. [57], } 2007\end{array}$ & Sweden & questionnaire & $\begin{array}{l}350 \text { needle exchangers } \\
(57 \% \text { amphetamine } \\
\text { users and } 42 \% \text { heroin } \\
\text { users) }\end{array}$ \\
\hline
\end{tabular}

$89 \%$ of heroin users and $24 \%$ of amphetamine users reported using buprenorphine during the past year. Intravenous misuse of buprenorphine was reported by $43 \%$ of illicit users and snorting by $29 \%$.

Man et al. [63], UK questionnaire 135 opiate users
2004

$56 \%$ of subjects presented a lifetime prevalence of opiate overdose. $66 \%$ of these patients reported mixing opiates with at least one other drug, especially alcohol and/or benzodiazepines.

\begin{tabular}{|c|c|c|c|c|}
\hline $\begin{array}{l}\text { Moratti } \\
\text { et al. [52], } 2010\end{array}$ & Italy & questionnaire & $\begin{array}{l}307 \text { buprenorphine or } \\
\text { methadone maintenance } \\
\text { treatment patients }\end{array}$ & $\begin{array}{l}23.1 \% \text { of patients admitted to intravenous } \\
\text { misuse of buprenorphine. }\end{array}$ \\
\hline $\begin{array}{l}\text { Roche et al. [54], } \\
2008\end{array}$ & Ireland & questionnaire & $\begin{array}{l}81 \text { opioid-dependent } \\
\text { patients in treatment }\end{array}$ & $\begin{array}{l}73 \% \text { of subjects reported methadone misuse } \\
\text { prior to treatment entry. } 55 \% \text { reported } \\
\text { methadone misuse during treatment. }\end{array}$ \\
\hline $\begin{array}{l}\text { Scherbaum } \\
\text { et al. [53], } 2005\end{array}$ & Germany & questionnaire & $\begin{array}{l}142 \text { opiate or poly- } \\
\text { addicted patients } \\
\text { consecutively admitted to } \\
\text { a detoxification ward }\end{array}$ & $\begin{array}{l}53.5 \% \text { of subjects misused medical opiates, } \\
\text { especially methadone. }\end{array}$ \\
\hline
\end{tabular}


Table 2 (continued)

\begin{tabular}{|c|c|c|c|c|}
\hline Reference & Country/region & Type of study & Sample & Results \\
\hline $\begin{array}{l}\text { Simojoki } \\
\text { et al. [59], } 2010\end{array}$ & Finland & $\begin{array}{l}\text { double-blind, } \\
\text { double-dummy, } \\
\text { randomized cross- } \\
\text { over design study }\end{array}$ & $\begin{array}{l}16 \text { opioid-dependent } \\
\text { patients }\end{array}$ & $\begin{array}{l}\text { Crushing buprenorphine tablets before } \\
\text { administering them to patients does not } \\
\text { significantly alter the drug's clinical effect. }\end{array}$ \\
\hline $\begin{array}{l}\text { Simonsen } \\
\text { et al. [41], } 2011\end{array}$ & $\begin{array}{l}\text { Nordic coun- } \\
\text { tries (Denmark, } \\
\text { Finland, Ice- } \\
\text { land, Norway, } \\
\text { Sweden) }\end{array}$ & $\begin{array}{l}\text { frequency analyses } \\
\text { (e.g. death rate, } \\
\text { place of death, sex } \\
\text { and age distribution, } \\
\text { cause of death) }\end{array}$ & $\begin{array}{l}\text { fatal poisonings in medi- } \\
\text { co-legally examined drug } \\
\text { addict deaths in the Nor- } \\
\text { dic countries between } \\
1991 \text { and } 2007\end{array}$ & $\begin{array}{l}\text { Whereas buprenorphine is the most frequent } \\
\text { cause of death among drug-dependent sub- } \\
\text { jects in Finland, accounting for } 25 \% \text { of intoxi- } \\
\text { cations in } 2007 \text {, methadone is the most fre- } \\
\text { quent cause of death in Denmark, constitut- } \\
\text { ing } 51 \% \text { of intoxications in the same year. }\end{array}$ \\
\hline $\begin{array}{l}\text { Stavropoulou } \\
{[61], 2011}\end{array}$ & Europe & $\begin{array}{l}\text { data analysis of the } \\
\text { European Social } \\
\text { Survey }\end{array}$ & $\begin{array}{l}45,700 \text { subjects from } 24 \\
\text { European countries }\end{array}$ & $\begin{array}{l}\text { General beliefs patients have about the doc- } \\
\text { tor-patient relationship (e.g. involvement in } \\
\text { decision-making process, treating patients as } \\
\text { equals, avoiding leaving unresolved issues } \\
\text { when prescribing medication) have been } \\
\text { found to significantly influence patients' deci- } \\
\text { sion to adhere to prescribed medication. }\end{array}$ \\
\hline
\end{tabular}

among subjects with drug dependence. Simonsen et al. [41] investigated drug-related deaths in the Nordic countries (Denmark, Finland, Iceland, Norway, and Sweden) from 1991 to 2007 and found that deaths from methadone overdose increased in all countries. Similarly, the number of buprenorphine intoxications in Sweden, Norway, and Finland also increased. Whereas buprenorphine is the most frequent cause of death among drug-dependent subjects in Finland, accounting for 25\% of intoxications in 2007, methadone is the most frequent cause of death in Denmark, constituting 51\% of intoxications in the same year. Toxicological screenings of drug-related deaths indicated widespread multidrug use in all countries (median number of drugs per case varied from 3 to 5). Commonly detected substances included heroin, methadone, buprenorphine, tramadol, amphetamine, cocaine, tetrahydrocannabinol, benzodiazepines, and ethanol.

\section{High-Risk Groups for the Misuse of Medicines Used for Opioid Substitution Therapy}

Drug users, especially heroin users, are doubtless the population most at risk of misusing substitution drugs. This group is also very prone to developing multiple substance dependence. A Spanish study on opioid-dependent patients admitted to methadone maintenance programs has found that $71.4 \%$ of patients displayed additional substance dependence diagnoses, such as co- caine or sedative dependence (using DSM-IV criteria) [51]. The misuse of multiple substances puts drug users at a particularly high risk for drug interactions and overdoses. A British study on opiate users from drug misuse treatment services found that $56 \%$ of subjects presented a lifetime prevalence of opiate overdose [63]. $66 \%$ of these patients reported mixing opiates with at least one other drug, especially alcohol and/or benzodiazepines (e.g. diazepam).

Table 2 displays a summary of the main reports on the misuse of medicines intended for opioid substitution therapy.

\section{Sedatives and Hypnotics}

Sedatives and hypnotics encompass a large group of substances that are generally used to treat symptoms of anxiety, stress and sleeping disorders. Benzodiazepines and Z-drugs are two of the most prescribed groups of sedatives/hypnotics. Benzodiazepines have a high potential for abuse and are often misused, making them one of the most relevant and researched groups of substances with respect to misuse. Among Germans dependent on prescription drugs, roughly $79-85 \%$ are estimated to be dependent on benzodiazepines [3]. Further evidence from Germany shows that the prevalence of dependence on sedatives and hypnotics in a representa- 
tive sample of general hospital patients was 1.4 and $1.2 \%$, respectively [37]. The misuse of benzodiazepines will not be reported here (see Introduction for a detailed discussion). Findings on the misuse of Z-Drugs are reported below.

\section{Z-Drugs}

Z-drugs are a group of nonbenzodiazepine hypnotics that were introduced in the mid to late 1980s as an alternative to the highly addictive benzodiazepines. Z-drugs such as zopiclone, zaleplon and zolpidem are used in the treatment of insomnia. Between 2001 and 2002, more than 1.3 billion zolpidem tablets were prescribed in $\mathrm{Eu}-$ rope, Japan and the USA; zopiclone prescriptions were approximately half as many (over 664 million) in Europe and Japan [64]. In 2002, the World Health Organization transferred zolpidem to schedule IV of the 1971 United Nations convention on psychotropic substances, thereby recognizing its high potential for misuse and dependence. Other dependence-inducing drugs such as benzodiazepines are also classified under this schedule. Nevertheless, the dependence potential and risk of misuse of $\mathrm{Z}$-drugs have been greatly debated in the scientific literature. In 2003, Hajak et al. [64] performed a systematic review of the literature between 1966 and 2002 to identify the risk of misuse and dependence of zolpidem and zopiclone. Their findings indicate that zolpidem and zopiclone are relatively safe drugs, but that certain groups may be more susceptible to substance misuse and dependence (see 'High-Risk Groups for the Misuse of Sedatives and Hypnotics'). A 2004 postmarketing study by Jaffe et al. [65] found similar results. This UK study surveyed intreatment drug and alcohol absusers as informants for assessing the relative misuse liability of sedatives/hypnotics and found that Z-drugs have a relatively low risk of misuse, comparable to that of sedating antidepressants and inferior to that of benzodiazepines. The German pharmacomonitoring system, Phar-Mon, found that Zdrugs account for a very small proportion of abused medicines within a small target group of subjects with substance use disorders [29]. Results from 2004 show that $0.4 \%$ of medicine misuse cases among opioid-dependent subjects could be traced back to zopiclone.

A more recent concurring French publication from 2007 which was conducted by the Nantes Centre for Evaluation and Information on Pharmacodependence (CEIP) indicates that zolpidem has a much higher risk of misuse than previously thought [66]. Results from this review suggest that pharmacokinetic factors such as rate of onset and half-life, which are believed to partial- ly determine a drug's reinforcing effects and misuse potential, should not differ significantly between benzodiazepines and zolpidem. Zolpidem has been found to be misused in order to induce anxiolytic and hypnotic effects. It has also been misused to induce euphoria and exaltation, which do not correspond to the active mechanisms of the drug. This second type of misuse has also been observed with the benzodiazepines triazolam and flunitrazepam. The study concludes that prevalence rates for zolpidem misuse and dependence are underreported, in part due to a lack of awareness of risks on behalf of clinicians and patients. The significant dependence and misuse potential of zolpidem indicates that this drug should only be prescribed with extreme caution to patients with a previous history of substance misuse.

\section{High-Risk Groups for the Misuse of Sedatives and} Hypnotics

A number of groups have been identified to be at risk for misusing Z-drugs. Data from the French CEIP found that elderly patients are generally more likely to be prescribed multiple anxiolytics and hypnotics and are at a higher risk for prescription medicine misuse [67]. In a Swedish study [68], individuals suffering from alcohol dependence have been found to be significantly more often dependent on benzodiazepines and zopiclone than healthy controls. Hajak et al. [64] also warn that former drug or alcohol abusers and patients with recognized psychiatric disorders appear to have an increased risk of Zdrug misuse. For this reason, extra caution should be taken when prescribing Z-drugs to these groups of patients. A representative epidemiological survey of schools in the Czech Republic found that nonprescribed sedatives and hypnotics were the second most commonly misused substance among teenagers 14-19 years of age (cannabis was the most commonly misused substance) [69]. These medicines were commonly misused in combination with alcohol. Finally, a cross-sectional study on a nationally representative sample of Hungarian women aged 15-24 was conducted in order to acquire epidemiological data on physical/sexual abuse and its relationship to health risk behaviors such as substance abuse [70]. Results suggest that women who had been abused by a parent or relative were significantly more likely to misuse marijuana and sedatives.

Table 3 displays a summary of the main reports on the misuse of sedatives/hypnotics. 
Table 3. Selected literature on the misuse of sedatives/hypnotics in the EU

\begin{tabular}{llll}
\hline Reference & $\begin{array}{l}\text { Country/ } \\
\text { region }\end{array}$ & Type of study & Sample \\
\hline
\end{tabular}

\begin{tabular}{|c|c|c|c|c|}
\hline $\begin{array}{l}\text { Csoboth } \\
\text { et al. [70], }\end{array}$ & Hungary & cross-sectional study & $\begin{array}{l}\text { nationally representative } \\
\text { sample of Hungarian }\end{array}$ & $\begin{array}{l}\text { Experiencing abuse by a partner was significantly } \\
\text { associated with sedative misuse, often in combi- }\end{array}$ \\
\hline
\end{tabular}

et al. [70],

2003

\begin{tabular}{|c|c|c|c|}
\hline $\begin{array}{l}\text { Fach } \\
\text { et al. [37], } \\
2007\end{array}$ & Germany & $\begin{array}{l}\text { self-administered } \\
\text { screening question- } \\
\text { naire and structured } \\
\text { psychiatric interview }\end{array}$ & $\begin{array}{l}952 \text { general hospital } \\
\text { patients }\end{array}$ \\
\hline
\end{tabular}

Hajak et al. Europe, literature review 36 cases of dependence
[64], $2003 \quad$ Japan, US on zolpidem, 22 cases of dependence on zopiclone nation with alcohol.

$1.4 \%$ prevalence of dependence on sedatives and $1.2 \%$ on hypnotics.

1.3 billion zolpidem prescriptions in Europe, Japan and the USA between 2001 and 2002.

Zopiclone prescriptions were approximately half as many in Europe and Japan. Findings indicate that zolpidem and zopiclone are relatively safe drugs, except for persons with a history of substance misuse/dependence.

\begin{tabular}{|c|c|c|c|c|}
\hline $\begin{array}{l}\text { Jaffe et al. } \\
\text { [65], 2004 }\end{array}$ & UK & survey & $\begin{array}{l}297 \text { in-treatment drug and } \\
\text { alcohol abusers }\end{array}$ & $\begin{array}{l}\text { Z-drugs have a relatively low risk of misuse, } \\
\text { comparable to that of sedating antidepressants } \\
\text { and inferior to that of benzodiazepines. }\end{array}$ \\
\hline
\end{tabular}

\begin{tabular}{|c|c|c|c|c|}
\hline $\begin{array}{l}\text { Micallef-Roll } \\
\text { and Lapeyre- } \\
\text { Mestre [67], } \\
2009\end{array}$ & France & $\begin{array}{l}\text { summary of the } \\
\text { CEIP meeting }\end{array}$ & $\mathrm{n} / \mathrm{a}$ & $\begin{array}{l}\text { Elderly patients are more likely to be prescribed } \\
\text { multiple anxiolytics and hypnotics and they are } \\
\text { at a higher risk for prescription medication } \\
\text { misuse. }\end{array}$ \\
\hline
\end{tabular}

Seblova et al. Czech survey

[69], 2005 Republic

8,334 respondents in 1994, Non-prescribed sedatives and hypnotics were 14,282 respondents the second most commonly misused substance, in 1997 , and 13,018 respondents in the year 2000 (14- to 19-year-olds)

\begin{tabular}{|c|c|c|c|c|}
\hline $\begin{array}{l}\text { Victorri- } \\
\text { Vigneau }\end{array}$ & France & literature review & 53 literature case reports & $\begin{array}{l}\text { Zolpidem has a significant dependence and } \\
\text { misuse potential. }\end{array}$ \\
\hline
\end{tabular}

\section{Discussion}

The misuse of medicines in Europe is an increasing issue of concern. With studies revealing that analgesics, sedatives and hypnotics, and drugs used for substitution treatment are being consumed in ways other than those medically intended and which can result in substance use disorders, this phenomenon merits increased awareness. Analgesics proved to be one of the most important groups of misused medicines, often in the context of pain treatment and/or simultaneous dependence on opioids. Part of the difficulty in controlling the misuse of analgesics in the context of pain treatment lies in the complexity of differentiating between patients with pain, those seeking 
treatment because of dependence and/or a propensity for diversion, and those presenting both characteristics. In order to reduce the risk of diversion, stronger restrictions can be placed on the prescription and distribution of analgesics. On the other hand, a stricter approach yields the risk of undermedicating pain patients, making pain therapy less effective [71,72]. One of the main challenges of policies that aim to reduce the misuse of analgesics is doing so in ways that do not interfere with appropriate pain treatment (i.e. balancing between increased accessibility of analgesics to optimize pain treatment and limited accessibility to decrease medicine misuse).

Similar problems arise with respect to medicines used for opioid substitution therapy (i.e. buprenorphine and methadone). Despite great efforts to control prescription, dispensing, and appropriate consumption, medicines used for substitution treatment have high rates of diversion. These drugs are practically exclusively misused by individuals who are under substitution treatment and who have a history of drug dependence (e.g. heroin dependence). Main motives of misuse include getting high and relieving withdrawal symptoms while patterns of misuse show that doctor shopping and buying and selling on the black market are common. In light of the studies cited above that suggest that deviant behavior, substandard prescribing practices, and stringent attitudes may be linked to doctor shopping, and that substandard prescribing practices may be linked to misuse, it is imperative to underline that these factors are in no way exhaustive. Ultimately, heroin-dependent patients display symptoms such as cravings, control loss, and continued use despite significant social, interpersonal or legal problems caused by substance use (refer to ICD-10 and DSM-IV). Doctor shopping could be seen as an example of control loss and infringement of the law that is driven by cravings. In any case, to a great extent, the factors associated with doctor shopping and drug misuse are still unclear. Taking France as an example of a country with relaxed prescribing regulations for buprenorphine substitution, the diversion and misuse of buprenorphine (e.g. black market, doctor shopping) may also result from its rather liberal availability as Fatseas and Auriacombe have pointed out [73]. One way to curb misuse without hindering access to treatment could include the implementation of prescription-monitoring programs. A recent French study on the impact of a prescription-monitoring program on doctor shopping for high dose buprenorphine found that monitoring can contribute to controlling doctor shopping without necessarily reducing access to treatment [74]. Another way to help optimize treatment could involve comparing physician and patient assessments of buprenorphine treatment. As Lavie et al. [75] have shown in a cross-sectional study comparing data from physician assessments to data from patient responses, obtaining buprenorphine without a prescription or with a prescription from another physician, intravenous administration of buprenorphine, benzodiazepine use, and depression were underestimated by prescribing physicians. Using these findings to improve communication and patient disclosure could help enhance treatment. In conclusion, the literature is unanimous regarding the high risk that illegal drug users have of misusing medicines intended for substitution treatment. Further research is of utmost importance for the optimization of treatment (e.g. through fulfillment of best-practice standards, intensified mentoring and therapy, the development of new medicines which more efficiently prevent misuse, the implementation of prescription-monitoring programs that do not reduce access to treatment) and for disentangling factors related to misuse.

Sedatives and hypnotics are the third large medicine group for which misuse and dependence play a significant role. The misuse of sedatives and hypnotics can be largely traced back to benzodiazepines and Z-drugs. Barbiturates, which have mostly been replaced by benzodiazepines in routine medical practice, appear to play a negligible role in prescription and misuse rates. Z-drugs have been found to be less immune to misuse and dependence than was initially hoped when they were introduced onto the market as an alternative to benzodiazepines. However, prevalence rates for misuse and dependence appear to be underreported, in part due to a lack of awareness of risks and to a certain level of overdosing, which is generally accepted by medical professionals. Although long-term treatment with Z-drugs is discouraged, this practice may also be generally accepted by medical professionals, additionally leading to underreporting of misuse and dependence [66]. Regarding highrisk groups, the elderly and patients with a history of substance misuse or dependence have an increased risk of $\mathrm{Z}$-drug misuse. However, the characteristics of misuse in these two groups are very different. Elderly individuals usually begin to misuse sedatives/hypnotics because of anxiety and sleeping problems related to old age. They are also more prone to receiving prescriptions for these ailments, exposing them to medicines with the potential for misuse and dependence. Other factors that precipitate medicine misuse among the elderly include social isolation, being female, and having a history of mental disorders. Misuse patterns for the elderly include doctor shop- 
ping, receiving medicines from family and friends, and medicine hoarding. Using this information, prevention measures could be tailored to prevent and reduce misuse among the elderly by preventing social isolation, treating mental disorders, cross-checking for multiple prescriptions to prevent doctor shopping, an so on. In comparison, the misuse patterns of individuals with a history of drug abuse include buying/selling sedatives and hypnotics on the black market, misuse in order to reduce withdrawal symptoms, and mixing sedatives and hypnotics with other drugs to modulate effects (e.g. mixing multiple sedatives to intensify sedating effects). Measures to reduce misuse in this population could include enforcing stricter controls and preventing the inadequate long-term prescription of Z-drugs.

When considering the implementation of legislative/ preventive measures for the reduction of medicine misuse and dependence in Europe, differences with respect to regulatory measures and to regional phenomena between European countries are of utmost importance. For example, while over-the-counter drugs in France are only allowed to be sold in pharmacies, in Germany some of them may be sold in pharmacies or drugstores, in the UK additionally in general stores, reflecting the UK's trend towards self-treatment $[33,76]$. Prices also fluctuate between countries: in Germany over-the-counter drugs are less expensive than prescribed drugs to encourage patients to self-medicate. The opposite is true in France, where over-the-counter drugs are often more expensive than prescription drugs as part of a policy which encourages patients to consult with physicians to obtain prescriptions for which they can be reimbursed [76]. Further research in this field could investigate the role of regulatory measures and regional differences on the misuse and dependence of medicines, as based on different European countries. Finally, medicine misuse has implications for every step of the production and distribution process (e.g. legislation, production, prescription and dispensing) [77]. Each of these steps needs to be taken into consideration in order to halt misuse.

This leads us to a discussion of the methodological limitations of this review. Despite careful consideration of the terminology used and the implementation of multiple searches, we cannot dismiss the possibility of having overlooked relevant reports. Medicine group names were used for the search instead of individual active pharmaceutical ingredients and registered trademarks (e.g. 'analgesics' instead of 'codeine, paracetamol or aspirin ${ }^{\circledR}$ '), with the exception of buprenorphine and methadone, which are by far the two most commonly used substanc- es for drug substitution treatment. This methodological choice allowed us to gain extensive knowledge on a broad group of medicines while limiting our results to specific medicines. The scarcity of hits with respect to medicines such as antidepressants, antiparkinson drugs, cough and cold medicines, and stimulants such as methylphenidate and modafinil is presumably due to the general nature of the searches performed. Indeed, a greater pool of literature on these topics exists [e.g. we are aware of multiple publications on neuroenhancement in Germany such as ref. 78-81] although this list is by no means exhaustive. In order to adequately review this volume of literature, a specific search, for example using active pharmaceutical ingredients, should be undertaken. Unfortunately, this goes beyond the scope of this review, which is focused on delivering a broader view of the main categories of misused medicines. Nevertheless, we would like to emphasize the importance of this line of research, especially with regard to the misuse of antidepressants and stimulants in the context of neuroenhancement.

Furthermore, there is a great deal of 'gray' literature which is not documented on large databases such as Web of Science and PubMed. This includes, among others, technical reports from government agencies or scientific research groups, working papers, and information which is not published in common scientific journals or is difficult to access. The acquisition of gray literature would require different methods (e.g. searching the internet, contacting governmental agencies and research groups personally). In order to estimate the extent of the problem in the framework of this systematic review, a questionnaire on medicine misuse was sent to all Reitox National Focal Points of the European Monitoring Centre for Drugs and Drug Addiction. The questionnaire gathered information on population surveys, high-risk groups, and terminology used with respect to medicine misuse, among other items. Main results showed heterogeneity across the EU with regards to terminology and data on medicine misuse.

This review reveals not only the extent of our knowledge on the misuse of medicines in the EU but also the shortcomings of our knowledge on the topic. For example, prevalence studies using representative samples of the general population were very rare, making assessments of rates of misuse and dependence on medicines across European countries difficult. Furthermore, literature from a number of European countries is missing, either because research on this topic is scarce in these countries or because publications are hard to access (e.g. gray literature, language barrier). Finally, studies which 
take multiple European countries into account are rare, again showing that research on medicine misuse in the EU is at an early stage and that the potential for growth within this field is large. A number of measures can be taken to improve our knowledge in the field of medicine misuse and dependence across Europe. First, prevalence studies within each European country could be performed to assess the extent of the problem. Second, prevalence studies should assess not only medicine types but also groups of people at risk. Thirdly, monitoring systems which are in place could be used to implement similar ones in countries which have no systematic way of monitoring medicine misuse and dependence. Finally, information exchange and networking between European countries would strengthen the dissemination of knowledge and resources and improve cooperation to gain better insight into medicine misuse across nations and implement policies that help reduce misuse.

\section{Acknowledgements}

The present study was carried out under the project 'Conceptualisation of a Methodology for Monitoring the Misuse of Medicines in Europe', which was funded by the European Monitoring Centre for Drugs and Drug Addiction (EMCDDA; contract No. 10.EPI.058.1.0). Work in preparing the manuscript and specific analyses was additionally supported by the 'Phar-Mon' project, which is funded by the German Federal Ministry of Health (FKZ No. IIA5-2511DSM302).

\section{Disclosure Statement}

The authors declare no conflicts of interest.

\section{References}

1 Report of the International Narcotics Control Board for 2006. International Narcotics Control Board. Geneva, United Nations, 2007

-2 Hernandez SH, Nelson LS: Prescription drug abuse: insight into the epidemic. Clin Pharmacol Ther 2010;88:307-317.

3 Glaeske G: Psychotrope und andere Arzneimittel mit Missbrauchs- und Abhängigkeitspotential (Psychotropic and other pharmaceuticals with abuse or dependence potential); in Deutsche Hauptstelle gegen die Suchtgefahren: Jahrbuch Sucht 2005. Geesthach, Neuland, 2005, pp 52-68.

$\checkmark 4$ Blanco C, Alderson D, Ogburn E, Grant BF, Nunes EV, Hatzenbuehler ML, Hasin DS: Changes in the prevalence of non-medical prescription drug use and drug use disorders in the United States: 1991-1992 and 20012002. Drug Alcohol Depend 2007;90:252260.

5 Kuehn BM: Prescription drug abuse rises globally. JAMA 2007;297:1306.

-6 Cicero TJ, Dart RC, Inciardi JA, Woody GE, Schnoll S, Munoz A: The development of a comprehensive risk-management program for prescription opioid analgesics: researched abuse, diversion and addiction-related surveillance (RADARS). Pain Med 2007;8:157-170.

7 Magrini N, Vaccheri A, Parma E, D’Alessandro R, Bottoni A, Occhionero M, Montanaro N: Use of benzodiazepines in the Italian general population: prevalence, pattern of use and risk factors for use (see comments). Eur J Clin Pharmacol 1996;50:19-25.
8 Zandstra SM, Furer JW, van de Lisdonk EH, van ' $t$ Hof M, Bor JHJ, van Weel C, Zitmann FG: Different study criteria affect the prevalence of benzodiazepine use. Soc Psychiatry Psychiatr Epidemiol 2002;37:139-144.

9 Stillwell G, Fountain J: Benzodiazepine Use - A Report of a Survey of Benzodiazepine Consumption in the Member Countries of the Pompidou Group. Geneva, World Health Organization, 2002.

10 Barbui C, Gregis M, Zappa M: A cross-sectional audit of benzodiazepine use among general practice patients. Acta Psychiatr Scand 1998;97:153-156.

11 Lagnaoui R, Depont F, Fourrier A, Abouelfath A, Bégaud B, Verdoux H, Moore N: Patterns and correlates of benzodiazepine use in the French general population. Eur J Clin Pharmacol 2004;60:523-529.

12 Pradel V, Delga C, Rouby F, Micallef J, Lapeyre-Mestre M: Assessment of abuse potential of benzodiazepines from a prescription database using 'doctor shopping' as an indicator. CNS Drugs 2010;24:611-620.

13 Lader M: Benzodiazepines revisited - will we ever learn? Addiction 2011;106:20862109.

14 Holzbach R: Benzodiazepine: longterm use and addiction (in German). Fortschr Neurol Psych 2012;78:425-431.

15 Heberlein A, Bleich S, Kornhuber J, Hillemacher T: Benzodiazepine dependence: causalities and treatment options. Fortschr Neurol Psych 2012;77:7-15.
16 Ashton $\mathrm{H}$ : The diagnosis and management of benzodiazepine dependence. Curr Opin Psychiatry 2005;18:249-255.

17 Lalive AL, Rudolph U, Luescher C, Tan KR: Is there a way to curb benzodiazepine addiction? Swiss Med Wkly 2011;141:w13277.

18 Siriwardena AN, Qureshi Z, Gibson S, Collier S, Latham M: GPs' attitudes to benzodiazepine and 'Z-drug' prescribing: a barrier to implementation of evidence and guidance on hypnotics. Br J Gen Pract 2006;56:964967.

19 Liebrenz M, Boesch L, Stohler R, Caflisch C: Agonist substitution - a treatment alternative for high-dose benzodiazepine-dependent patients? Addiction 2010;105:18701874

20 Kanayama G, Hudson JI, Pope HG: Illicit anabolic-androgenic steroid use. Horm Behav 2010;58:111-121.

21 Mattila VM, Rimpelä A, Jormanainen V, Sahi T, Pihlajamäki H: Anabolic-androgenic steroid use among young Finnish males. Scand J Med Sci Sports 2010;20:330-335.

22 Wanjek B, Rosendahl J, Strauss B, Gabriel $\mathrm{HH}$ : Doping, drugs and drug abuse among adolescents in the state of Thuringia (Germany): prevalence, knowledge and attitudes. Int J Sports Med 2007;28:346-353.

23 Dodge T, Hoagland MF: The use of anabolic androgenic steroids and polypharmacy: a review of the literature. Drug Alcohol Depend 2011;114:100-109.

24 Handelsman DJ: Androgen misuse and abuse. Best Pract Res Clin Endocrinol Metab 2011;25:377-389. 
25 Palmié N, Condemine-Piron C, Peyrière H, Eiden C, Blayac J: Dependence on anabolic androgenic steroids in sport: a retrospective study of phone calls at 'ecoute dopage' hotline. Fundam Clin Pharmacol 2011;25(s1):20.

-26 Sjöqvist F, Garle M, Rane A: Use of doping agents, particularly anabolic steroids, in sports and society. Lancet 2008;371:18721882.

27 Barrett SP, Meisner JR, Stewart SH: What constitutes prescription drug misuse? Problems and pitfalls of current conceptualizations. Curr Drug Abuse Rev 2008;1:255-262.

28 American Psychiatric Association: Diagnostic and Statistical Manual of Mental Disorders. Washington, American Psychiatric Association, 2000.

29 Kufner H, Rosner S: Monitoring of the misuse of prescription drugs by clients of outpatient addiction treatment centres (PHARMON, formerly: Ebis-med) - Monitoring of medication misuse (in German). Gesundheitswesen 2008;70:305-314.

-30 Gjerden P, Bramness JG, Slordal L: The use and potential abuse of anticholinergic antiparkinson drugs in Norway: a pharmacoepidemiological study. Br J Clin Pharmacol 2009;67:228-233.

- 31 Frauger E, Thirion X, Chanut C, Natali F, Debruyne D, Saillard C, Pradel V, Reggio P, Micallef J: Misuse of trihexyphenidyl $\left(\right.$ Artane ${ }^{\circledR}$, Parkinane ${ }^{\circledR}$ ): recent trends (in French). Therapie 2003;58:541-547.

- 32 Orriols L, Gaillard J, Lapeyre-Mestre M, Roussin A: Evaluation of abuse and dependence on drugs used for self-medication a pharmacoepidemiological pilot study based on community pharmacies in France. Drug Safety 2009;32:859-873.

33 MacFadyen L, Eadie D, McGowan T: Community pharmacists' experience of over-thecounter medicine misuse in Scotland. J R Soc Promot Health 2001;121:185-192.

- 34 Franke AG, Bonertz C, Christmann M, Huss M, Fellgiebel A, Hildt E, Lieb K: Non-medical use of prescription stimulants and illicit use of stimulants for cognitive enhancement in pupils and students in Germany. Pharmacopsychiatry 2011;44:60-66.

- 35 Frauger E, Pauly V, Pradel V, Reggio P, Coudert $\mathrm{H}$, Thirion X, Micallef J: Patterns of methylphenidate use and assessment of its abuse and diversion in two French administrative areas using a proxy of deviant behaviour determined from a reimbursement database main trends from 2005 to 2008. CNS Drugs 2011;25:415-424.

-36 Porteous T, Bond C, Hannaford P, Sinclair H: How and why are non-prescription analgesics used in Scotland? Fam Pract 2005;22: $78-85$.
Fach M, Bischof G, Schmidt C, Rumpf HJ: Prevalence of dependence on prescription drugs and associated mental disorders in a representative sample of general hospital patients. Gen Hosp Psychiatry 2007;29:257263.

38 Fredheim OMS, Skurtveit S, Moroz A, Breivik H, Borchgrevink PC: Prescription pattern of codeine for non-malignant pain: a pharmacoepidemiological study from the Norwegian Prescription Database. Acta Anaesthesiol Scand 2009;53:627-633.

39 Armand C, Thirion X, Saillard C, LapeyreMestre M, Lambert H: Neocodion ${ }^{\circledR}$ misuse: Evolution between 1992 and 2002. Therapie 2004;59:547-553.

-40 Tjaderborn M, Jonsson AK, Ahlner J, Hagg $S$ : Tramadol dependence: a survey of spontaneously reported cases in Sweden. Pharmacoepidemiol Drug Saf 2009;18:1192-1198.

-41 Simonsen KW, Normann PT, Ceder G, Vuori E, Thordardottir S, Thelander G, Hansen AC, Teige B, Rollmann D: Fatal poisoning in drug addicts in the Nordic countries in 2007. Forensic Sci Int 2011;207:170-176.

42 Gibaja V, Seyer D, Lambert H, Kahn J: Prescription and misuse of fentanyl: results from a survey from the Medical Department of North East Social Security (France), over years 2007-2009. Fundam Clin Pharmacol 2011;25:75

43 Beau-Salinas F, Jonville-Bera AP, Cissoko H, Bensouda-Grimaldi L, Autret-Leca E: Drug dependence associated with triptans and ergot derivatives: a case/non-case study. Eur J Clin Pharmacol 2010;66:413-417.

44 Perearnau P, Vuillemet F, Schick J, Weill G: Patterns of prescription and usage of triptans in Alsace (France): misuse is frequent and avoidable (in French). Rev Neurol (Paris) 2006;162:347-357.

45 Bramness JG, Furu K, Engeland A, Skurtveit $S$ : Carisoprodol use and abuse in Norway. A pharmacoepidemiological study. Br J Clin Pharmacol 2007;64:210-218.

46 Hojsted J, Sjogren P: Addiction to opioids in chronic pain patients: a literature review. Eur J Pain 2007;11:490-518.

47 Radat F, Creac'h C, Guegan-Massardier E, Mick G, Guy N, Fabre N, Giraud P, NachitOuinekh F, Lanteri-Minet M: Behavioral dependence in patients with medication overuse headache: a cross-sectional study in consulting patients using the DSM-IV criteria. Headache 2008;48:1026-1036.

48 Lundqvist C, Aaseth K, Grande RB, Benth JS, Russell MB: The severity of dependence score correlates with medication overuse in persons with secondary chronic headaches. The Akershus study of chronic headache. Pain 2010;148:487-491.

49 Stafford N: At least $25 \%$ of elderly residents of German nursing homes are addicted to psychotropic drugs, report claims. Br Med J 2010;340.
50 Leikola S, Dimitrow M, Lyles A, Pitkälä K, Airaksinen M: Potentially inappropriate medication use among Finnish non-institutionalized people aged $\geq 65$ years: a registerbased, cross-sectional, national study. Drugs Aging 2011;28:227-236

51 Astals M, Domingo-Salvany A, Buenaventura CC, Tato J, Vazquez JM, Martin-Santos $\mathrm{R}$, Torrens M: Impact of substance dependence and dual diagnosis on the quality of life of heroin users seeking treatment. Subst Use Misuse 2008;43:612-632.

52 Moratti E, Kashanpour H, Lombardelli T, Maisto M: Intravenous misuse of buprenorphine characteristics and extent among patients undergoing drug maintenance therapy. Clin Drug Investig 2010;30:3-11.

53 Scherbaum N, Kluwig J, Meiering C, Gastpar M: Use of illegally acquired medical opioids by opiate-dependent patients in detoxification treatment. Eur Addict Res 2005;11:193196.

54 Roche A, McCabe S, Smyth BP: Illicit methadone use and abuse in young people accessing treatment for opiate dependence. Eur Addict Res 2008;14:219-225.

55 Pauly V, Frauger E, Pradel V, Rouby F, Berbis J, Natali F, Reggio P, Coudert H, Micallef J, Thirion X: Which indicators can public health authorities use to monitor prescription drug abuse and evaluate the impact of regulatory measures? Controlling High Dosage Buprenorphine abuse. Drug Alcohol Depend 2011;113:29-36.

56 Cazorla C, de Cardenal DG, Schuhmacher H, Thomas L, Wack A, May T, Rabaud C: Infectious complications and misuse of highdose buprenorphine (in French). Presse Med 2005;34:719-724.

-57 Hakansson A, Medvedeo A, Andersson M, Berglund M: Buprenorphine misuse among heroin and amphetamine users in Malmo, Sweden: purpose of misuse and route of administration. Eur Addict Res 2007;13:207215.

58 Alho H, Sinclair D, Vuori E, Holopainen A: Abuse liability of buprenorphine-naloxone tablets in untreated IV drug users. Drug Alcohol Depend 2007;88:75-78.

59 Simojoki K, Lillsunde P, Lintzeris N, Alho $\mathrm{H}$ : Bioavailability of buprenorphine from crushed and whole buprenorphine (Subutex) tablets. Eur Addict Res 2010;16:85-90.

60 Feroni I, Peretti-Watel P, Paraponaris A, Masut A, Ronfle E, Mabriez JC, Obadia Y: French general practitioners' attitudes and prescription patterns toward buprenorphine maintenance treatment: does doctor shopping reflect buprenorphine misuse? J Addict Dis 2005;24:7-22.

61 Stavropoulou C: Non-adherence to medication and doctor-patient relationship: evidence from a European survey. Patient Educ Couns 2011;83:7-13. 
62 Bacha J, Reast S, Pearlstone A: Treatment practices and perceived challenges for European physicians treating opioid dependence. Heroin Addict Rel Clin Probl 2010;12:9-19.

-63 Man LH, Best D, Gossop M, Stillwell G, Strang J: Relationship between prescribing and risk of opiate overdose among drug users in and out of maintenance treatment. Eur Addict Res 2004;10:35-40.

64 Hajak G, Muller WE, Wittchen HU, Pittrow D, Kirch W: Abuse and dependence potential for the non-benzodiazepine hypnotics zolpidem and zopiclone: a review of case reports and epidemiological data. Addiction 2003; 98:1371-1378.

65 Jaffe JH, Bloor R, Crome I, Carr M, Alam F, Simmons A, Meyer RE: A postmarketing study of relative abuse liability of hypnotic sedative drugs. Addiction 2004;99:165-173.

66 Victorri-Vigneau C, Dailly E, Veyrac G, Jolliet P: Evidence of zolpidem abuse and dependence: results of the French Centre for Evaluation and Information on Pharmacodependence (CEIP) network survey. Br J Clin Pharmacol 2007;64:198-209.

67 Micallef-Roll J, Lapeyre-Mestre M: Second Meeting of the French CEIP (Centres d'Evaluation et d'Information sur la Pharmacodépendance). I. How to evaluate and prevent the abuse and dependence on hypnotic/anxiolytic drugs? Therapie 2009;64: 355-364.
68 Johansson BA, Berglund M, Hanson M, Pohlen C, Persson I: Dependence on legal psychotropic drugs among alcoholics. Alcohol Alcohol 2003;38:613-618.

69 Seblova J, Polanecky V, Sejda J, Studnickova B: Trends in substance abuse by teenagers in the Czech Republic. J Emerg Med 2005;28: 95-100.

70 Csoboth CT, Birkas E, Purebl G: Physical and sexual abuse: risk factors for substance use among young Hungarian women. Behav Med 2003;28:165-171.

71 Hurwitz W: The challenge of prescription drug misuse: a review and commentary. Pain Med 2005;6:152-161.

72 DuPont RL: Prescription drug abuse: an epidemic dilemma. J Psychoactive Drugs 2010; 42:127-132.

73 Fatseas M, Auriacombe M: Why buprenorphine is so successful in treating opiate addiction in France. Curr Psychiatry Rep 2007; 9:358-364.

74 Pradel V, Frauger E, Thirion X, Ronfle E, Lapierre V, Masut A, Coudert C, Blin O, Micallef J: Impact of a prescription monitoring program on doctor-shopping for high dosage buprenorphine. Pharmacoepidemiol Drug Saf 2009;18:36-43.
75 Lavie E, Fatséas M, Daulouède JP, Denis C, Dubernet J, Cattan L, Auriacombe M: Comparison of prescriber evaluations and patient-directed self-reports in office-based practice for buprenorphine treatment of opiate-dependent individuals in France, 2002. Patient Prefer Adherence 2008;2:369-378.

76 Bergmann JF: Self-medication: from European regulatory directives to therapeutic strategy. Fundam Clin Pharmacol 2003;17: 275-280.

77 Fermont I: Misuse of drugs: conclusions of the pharmacovigilance workshops in La Baule, France. Therapie 2002;57:283-288.

78 Repantis D, Schlattmann P, Laisney O, Heuser I: Modafinil and methylphenidate for neuroenhancement in healthy individuals: a systematic review. Pharmacol Res 2010;62: 187-206.

79 Deutsche Angestellten Krankenkasse (DAK). Gesundheitsreport 2009: Analyse derArbeitsunfähigkeitsdaten. Schwerpunktthema Doping am Arbeitsplatz. Hamburg, DAK, 2009.

80 Robert Koch-Institut (RKI): KOLIBRI Studie zum Konsum Leistungsbeeinflussender Mittel in Alltag und Freizeit: Ergebnisbericht. Berlin, RKI, 2011.

81 Deutsche Hauptstelle für Suchtfragen (DHS). Hirndoping: die Position der Deutschen Hauptstelle für Suchtfragen e.V. (DHS). Hamm, DHS, 2011. 